\title{
Practices About Antibiotic Use Among Urban Residents: A Cross-Sectional Survey in Rufisque, Senegal
}

\author{
Oumar Bassoum ${ }^{1,2, \text { *, Mamadou Makhtar Mbacke Lèye }}{ }^{1,2}$, Ndèye Marème Sougou ${ }^{1,2}$, \\ Mayassine Diongue $^{1,2}$, Khadim Niang ${ }^{1,2}$, Jean Augustin Diegane Tine ${ }^{1,2}$, Mouhamad Mbodji ${ }^{3}$, \\ Adama Faye $^{1,2}$, Ibrahima Seck ${ }^{1,2}$, Djibril Fall ${ }^{3}$, Anta Tal-Dia ${ }^{1,2}$ \\ ${ }^{1}$ Department of Public Health and Preventive Medicine, Faculty of Medicine, Pharmacy and Odontology, University Cheikh Anta Diop, \\ Dakar, Senegal \\ ${ }^{2}$ Institute of Health and Development, University Cheikh Anta Diop, Dakar, Senegal \\ ${ }^{3}$ Laboratory of Therapeutic and Organic Chemistry, Faculty of Medicine, Pharmacy and Odontology, University Cheikh Anta Diop, Dakar, \\ Senegal
}

\author{
Email address: \\ bassoum.oumar@gmail.com (O. Bassoum), oumar.bassoum $a$ ucad.edu.sn (O. Bassoum) \\ ${ }^{*}$ Corresponding author
}

\section{To cite this article:}

Oumar Bassoum, Mamadou Makhtar Mbacke Lèye, Ndèye Marème Sougou, Mayassine Diongue, Khadim Niang, Jean Augustin Diegane Tine, Mouhamad Mbodji, Adama Faye, Ibrahima Seck, Djibril Fall, Anta Tal-Dia. Practices About Antibiotic Use Among Urban Residents: A Cross-Sectional Survey in Rufisque, Senegal. Central African Journal of Public Health. Vol. 5, No. 1, 2019, pp. 1-12. doi: 10.11648/j.cajph.20190501.11

Received: November 17, 2018; Accepted: December 3, 2018; Published: January 21, 2019

\begin{abstract}
Antibiotics have saved millions of lives around the world. However, their effectiveness is compromised by the emergence and spread of antibiotic resistance. The latter is a threat to global health. Under the International Health Regulations, a national self-assessment was conducted in Senegal to assess the country's capacity to cope with this scourge. It is followed by the joint external evaluation of the World Health Organization. One of the main recommendations is raising public awareness about the rational use of antibiotics. The goal of this study was to evaluate the general public's practices regarding antibiotics and the determinants of antibiotic use without a medical prescription. The study was cross-sectional. It was conducted at the Rufisque bus station. Rufisque is a city located in the region of Dakar, capital of Senegal. We estimated the sample size using Raosoft. Participants were selected according to a convenience sampling. A questionnaire was administered in an individual interview. Logistic regression was used to identify the determinants of antibiotic use without a prescription. A total of 400 people were included. Among them, 75\% (300/400) said they had taken antibiotics during the last twelve months. The sources of supply were the community pharmacy $(81 \%)$, the entourage $(12 \%)$, the remaining antibiotics $(5 \%)$ and the illicit drugs market (2\%). The use of antibiotics without a prescription was reported by $75 \%$ of participants $(225 / 300)$. It was more common among the uneducated people ( $\mathrm{OR}=2.7, \mathrm{P}=.002)$. In addition, $16.8 \%(67 / 400)$ said they had shared their antibiotic treatment with their relatives or friends. Shortening the duration and frequency of antibiotic treatment was found in $65.8 \%(263 / 400)$ and $29.3 \%$ (117/400) of respondents, respectively. About 7\% (29/400) said they sometimes demand antibiotics to prescribers. Almost all $(98.8 \%, 395 / 400)$ stated that they had never returned unwanted medicines to pharmacies or health facilities while $37.8 \%$ (151/400) said they had never checked the expiry dates of medicines. This study, conducted in an urban setting, showed that respondents have recourse to inadequate practices toward antibiotics. We recommend the sensitization of populations especially those who are not educated. Other studies should be conducted mainly in rural areas to identify the most commonly used antibiotics and the extent of inappropriate practices and their determinants.
\end{abstract}

Keywords: Practices, General Public; Antibiotic Use, Antibiotic Resistance, Rufisque, Senegal 


\section{Introduction}

An antibiotic is a chemical substance, produced by microorganisms, that has the ability to prevent growth of and to even destroy bacteria and other microorganisms [1]. The modern era of antibiotics began with the discovery of penicillin by Sir Alexander Fleming in 1928 [2]. Then, the period 1940-1970 represents the golden age of antibiotics with the development of new antibacterial agents [1]. These include, among others, tetracycline, erythromycin, methicillin and gentamicin [2]. Antibiotics have saved millions of lives. In developing countries, marked by poor sanitation, they have significantly reduced morbidity and mortality due to food-borne and poverty-related infections [2]. However, bacterial resistance has occurred in parallel with the discovery of antibiotics [2]. This situation was already predicted by Sir Alexander Fleming who claimed that one day the world would face bacterial resistance [3]. This prediction has become a reality. The situation is worrying since the development of new antibiotics has significantly declined since the 1970s [1]. No new class of antibiotics has been discovered since the 1980s. The majority of antibacterial agents that have been introduced since then are chemical modifications of known antibiotics classes [4]. Pharmaceutical companies do not feel deriving much benefit from research and development of new antibiotics [5]. Thus, they prefer to invest in research and development of drugs used to combat chronic diseases and improve lifestyles [5]. According to the Director of the WHO Antimicrobial Resistance Secretariat, Dr. Marc Sprenger, there is little hope of developing new antibiotics. He estimates that one or two new antibiotics are expected in the next seven years [6]

Antibiotic resistance occurs when an antibiotic loses its ability to inhibit bacterial growth [7]. It is a natural process. However, it is strongly associated with the misuse and overuse of antibiotics that involve both health care providers and patients [3]. On the one hand, some antibiotic prescribing practices are irrational [5]. Added to this is the dispensing of antibiotics without a medical prescription [2], sometimes even by unqualified persons [5]. On the other hand, patients' practices with regard to antibiotics promote the occurrence of bacterial resistance. This is self-medication, sharing of antibiotics and non-compliance with treatment $[3,5]$. Similarly, some patients ask health professionals to prescribe antibiotics for them without knowing if they are needed or not [8].

Antibiotic resistance is a major public health problem worldwide. It concerns several pathogens encountered both in the hospitals and community setting [8]. The most commonly reported resistant bacteria are Escherichia coli, Klebsiella pneumoniae, Staphylococcus aureus, Streptococcus pneumoniae and Salmonella spp [9].

The WHO report published in 2014 highlighted the high levels of resistance to most commonly used antibiotics. For example, the prevalence of fluoroquinolones and thirdgeneration cephalosporins resistance in Escherichia coli is estimated at $100 \%$ and $97 \%$ in Europe, respectively. In Africa, this prevalence is $74 \%$ and $68 \%$, respectively [10].
This report also reveals cases of carbapenems resistance in Klebsiella pneumonia. In the WHO African region, this resistance is detected in $57 \%$ of cases while in the WHO region of the Americas it is $100 \%$ [10]. Recently cases of colistin resistance have been reported in the United States [11] and China [12].

In Senegal, Camara $\mathrm{M}$ et al. demonstrated carbapenems and beta-lactams resistance in enterobacteriaceae with respective proportions of $5.1 \%$ and $26.2 \%$ [13]. The most affected pathogens are Escherichia coli and Klebsiella pneumonia [13].

According to Jim O'Neill's 2016 report, 700,000 people die each year from resistant infections [8]. This report reveals that, by 2050 , these infections could cause 10 million deaths per year. The economic cost is also enormous since global production losses are estimated at $\$ 100$ trillion by 2050 . Bacterial resistance would make medical procedures such as caesarean section, chemotherapy, organ transplantation and joint replacement surgery more dangerous [8]. It could be comparable to climate change [3] or worse than the 2008 financial crisis [14]. The impact of the threat will be greater in resource-poor countries [8] where antibiotics of last resort are not widely available [9].

In view of the extent of bacterial resistance and its clinical and economic consequences, it is important to put in place strategies to limit the inappropriate use of antibiotics. These are based on awareness and prevention and control of infections [5].

Initiatives are being taken internationally. First, in 2015, the WHO developed a global action plan to tackle antimicrobial resistance [7]. Its aim is "to ensure, for as long as possible, continuity of successful treatment and prevention of infectious diseases with effective and safe medicines that are quality-assured, used in a responsible way, and accessible to all who need them". This plan is based on strategic goals including awareness and optimization of antimicrobial medicines use [7].

Then, the WHO set up the Global Antimicrobial Resistance Surveillance System (GLASS) [9]. It supports the global action plan on AMR. Its purpose is to promote a standardized approach for the collection, analysis and reporting data on antimicrobial resistance at the global level in order to inform decision-making and support local action. The system advocates close collaboration between member states. Eight bacterial agents are retained in the initial phase of GLASS implementation. These are Acinetobacter spp., Escherichia coli, Klebsiella pneumoniae, Neisseria gonorrhoeae, Salmonella spp., Shigella spp., Staphylococcus aureus and Streptococcus pneumoniae [9].

Similarly, a non-governmental organization called "World Alliance Against Antibiotic Resistance" (WAAAR) was created in 2011. The NGO made recommendations that included raising public awareness, monitoring antibiotics use, and listing the "concept of antibiotic" in the UNESCO list of intangible cultural heritage [15]. Since 2015, the WAAAR has produced an annual publication, AMR Control, which promotes important strategies to fight against antibiotic 
resistance [16].

In Senegal, actions are also initiated. For example, there is a governance framework for the control of healthcareassociated infections [17]. In addition, a national selfassessment was conducted to measure the country's readiness to cope with AMR. It was followed by the joint external evaluation (JEE) conducted by the WHO as part of the International Health Regulations. The JEE highlighted two major shortcomings. First, the weakness of the pathogen surveillance system is noted. Second, the irrational use of antibiotics is found and is manifested through inadequate prescribing practices, self-medication and the existence of an illicit market for medicines [18]. The main recommendations are to promote rational use of antimicrobials, develop a multi-sectoral action plan and conduct surveys on antibiotic use [18]. In view of these recommendations, it appeared necessary to conduct a study on antibiotics use in the general population. It enables to identify gaps in people' behavior towards antibiotics and consequently set up relevant awareness campaigns. In Senegal, little is known about the level and conditions of antibiotics consumption. This study represents an important opportunity to help address this gap. Its objective was to evaluate populations' practices with regard to antibiotics and the determinants of their use without medical prescription.

\section{Methods}

\subsection{Study Setting}

The study took place at the Rufisque bus station. Rufisque is the chief town of the department of the same name. The latter belongs to the region of Dakar, capital of Senegal.

In 2017 , the population of the municipality of Rufisque was estimated at 248696 inhabitants [19]. In the department, the place reserved for hand washing was only observed in $23.8 \%$ of households. Of these, only $19.7 \%$ had water and soap at this place.

Immunization coverage among children aged 12 to 23 months was $76.4 \%$. Among those aged under five, the respective prevalence of diarrhea and acute respiratory infections were $16.3 \%$ and $2.2 \%$ [20].

\subsection{Type and Period of Study}

This study was cross-sectional and was conducted from November 25 to December 25, 2017.

\subsection{Study Population}

The study population consisted of people met at the Rufisque bus station.

\subsubsection{Inclusion Criteria}

The people included in the study were those aged 18 years and over.

\subsubsection{Non-inclusion Criteria}

Health professionals and medical/paramedical field students and the people who refused to participate were not included in the study.

\subsection{Sample Size}

Raosoft sample size calculator was used [21]. To the best of our knowledge, no study that assessed general public' practices about antibiotics use was conducted in Senegal. Thus, the expected response distribution was estimated at $50 \%$ [21]. In this study, source population size was unknown since it consisted of people met at the Rufisque bus station. According to Raosoft, faced with this situation, source population size can be estimated at 20,000 people [21]. A margin of error of $5 \%$ and a confidence level of $95 \%$ were accepted [21].

Thus, the number of subjects required was 377. This number was rounded to 400 in order to optimize sample representativeness.

\subsection{Sampling Procedure}

A convenience sampling was used. Participants were included using a consecutive recruitment until the number of 400 persons was reached. Participation was voluntary. Anyone who met the inclusion criteria and refused to participate was replaced by the next, and so on.

\subsection{Data Collection}

\subsubsection{Collection Tool}

The research instrument was a questionnaire that was developed by two academic researchers in Public Health/Epidemiology and Therapeutic and Organic Chemistry, respectively. The questionnaire was reviewed by all co-authors who have extensive experience in conducting epidemiological surveys. It was previously tested on sixteen people. It was reviewed and improved based on feedback from the pre-test. Some questions were reworded while others were deleted.

The final version of the collection tool consisted of two sections. The first allowed us to collect the participants' socio-demographic characteristics through seven questions (age, gender, marital status, professional status, education, distance between the place of residence and a health facility and distance between place of residence and a community pharmacy).

The second section focused on participants' practices regarding antibiotics use. The first question was about antibiotic consumption in the last 12 months preceding the survey. The second question allowed knowing if the participant has already had to share his antibiotic treatment with his entourage. The third and fourth questions assessed participants' compliance to antibiotic treatment (duration and frequency).

The fifth question was whether patients demand for antibiotics from prescribers or not.

The sixth and seventh questions collected participants' practices about verifying drugs expiry dates and returning of expired or unused drugs to pharmacies or health facilities. 
Answers for questions 1-5 were "yes", "no" or "don't remember". For questions 6 and 7, the answer options were " never ", " rarely " or " always ".

Respondents who answered yes to questions were asked to indicate the sources of supply for their antibiotic treatment (question 1) and the reasons for their practices (questions 14).

\subsubsection{Collection Method}

The data was collected by a sixth-year pharmacy student during a face-to-face interview. As part of this study, the interviewer was made aware of the context, rationale, objectives and methodology of the study and was trained on how to administer a questionnaire. This questioner stood at the entrance to the bus station and administered the questionnaire to those who met the inclusion criteria. The survey started every day at 8 am and ended at $1 \mathrm{pm}$. The questioner was able to contact a supervisor at any time to resolve some difficulties encountered in the field. Every evening, a report is prepared to ensuring data quality.

\subsection{Data Entry and Analysis}

The data were entered into a Microsoft Excel (version 2010). They were analyzed using Epi Info 7. The variables were described as numbers (n) and percentages (\%). The purpose of the analytical part was to identify the factors associated with the use of antibiotics without a prescription (UAWP). The dependent variable was the UAWP. It was binary (yes / no). The independent variables were participants' socio-demographic characteristics (SDC).

We estimated the prevalence of the UAWP among those who consumed antibiotics in the last 12 months preceding the survey. A bivariate analysis was conducted using chi-square independence test and odds ratio (OR). According to Hosmer DWJ and Lemeshow S, any variable whose p-value was less than 0.25 was included in the multivariate analysis using logistic regression [22]. The statistical signification was set at 0.05 .

\subsection{Ethical Considerations}

The study was conducted as part of a Pharm. D thesis. It was non-interventional. It did not involve human or animal tissue. The administration of the questionnaire did not offend the participant since it lasted on average ten minutes. The study had no impact on the environment. The participation was voluntary. Free and informed consent was collected from each respondent prior to inclusion in the study. The participant was informed about the opportunity to withdraw from the study at any time. If so, the participant was not forced to explain oneself. Confidentiality and anonymity were respected.

\section{Results}

\subsection{Participation Rate-Completeness Rate}

The participation was voluntary. The study stopped after reaching the required number of subjects (400). Thus, the participation rate was $100 \%$. All questionnaires were fully completed $(100 \%)$.

\subsection{Participants'Socio-demographic Characteristics}

Most respondents were in the age group [31-40] years $(32.5 \%)$, male $(55 \%)$ and married $(55.5 \%)$. They were employed in most cases $(62 \%)$. Nearly half were educated (48.75\%). Finally, $49.25 \%$ and $68.5 \%$ lived near a health facility and a community pharmacy, respectively (Table 1).

Table 1. Participants' socio-demographic characteristics, Rufisque, Senegal November-December $2017(N=400)$.

\begin{tabular}{|c|c|c|}
\hline Socio-demographic characteristics & $\mathbf{n}$ & $\%$ \\
\hline \multicolumn{3}{|l|}{ Age group (years) } \\
\hline$[18-30]$ & 114 & 28.5 \\
\hline$[31-40]$ & 130 & 32.5 \\
\hline$[41-50]$ & 87 & 21.8 \\
\hline$[51-60]$ & 43 & 10.8 \\
\hline$[>60]$ & 26 & 6.5 \\
\hline \multicolumn{3}{|l|}{ Gender } \\
\hline Male & 220 & 55 \\
\hline Female & 180 & 45 \\
\hline \multicolumn{3}{|l|}{ Marital status } \\
\hline Married & 222 & 55.5 \\
\hline Unmarried & 178 & 44.5 \\
\hline \multicolumn{3}{|l|}{ Professional status } \\
\hline Employed & 248 & 62 \\
\hline Unemployed & 152 & 38 \\
\hline \multicolumn{3}{|l|}{ Education } \\
\hline Yes & 195 & 48.75 \\
\hline No & 205 & 51.25 \\
\hline \multicolumn{3}{|l|}{ Proximity to a health facility } \\
\hline Yes $(<300$ meters $)$ & 197 & 49.25 \\
\hline No (> 300 meters $)$ & 203 & 50.75 \\
\hline \multicolumn{3}{|l|}{ Proximity to a community pharmacy } \\
\hline Yes $(<300$ meters $)$ & 274 & 68.5 \\
\hline No (>300 meters) & 126 & 31.5 \\
\hline
\end{tabular}

\subsection{Practices}

\subsubsection{Antibiotic Consumption}

Three-quarters $(75 \%, 300 / 400)$ of people said they had taken antibiotics in the last 12 months before the survey (Table 2). Among them, 75\% (225/300) used antibiotics without a prescription (Figure 1).

\subsubsection{Antibiotics'Sharing}

This study showed that $16.8 \%$ of people had already shared antibiotics with other people (Table 2).

\subsubsection{Treatment Noncompliance}

The majority $(65.8 \%)$ of the participants admitted to having already discontinued antibiotic therapy. At the same time, $29.3 \%$ said that they had already reduced the frequency taken (Table 2).

\subsubsection{Demand for Antibiotics}

About $7 \%$ of people stated that they sometimes demand antibiotics from the prescribers (Table 2). 


\subsubsection{Home Storage of medicines}

Almost all (98.8\%) of people said they had never returned expired or unused drugs to pharmacies or health facilities (Table 2).

\subsubsection{Checking Drugs' Expiration Dates}

More than one-third (37.8\%) of people never checked the drugs' expiration dates (Table 2).

Table 2. Participants 'practices towards antibiotic use, Rufisque, Senegal, November-December $2017(N=400)$.

\begin{tabular}{|c|c|c|c|}
\hline \multirow[b]{2}{*}{ Questions } & \multicolumn{3}{|l|}{ Responses } \\
\hline & Yes & No & $\begin{array}{l}\text { Don't } \\
\text { remember }\end{array}$ \\
\hline Have you taken any antibiotic treatment in the last 12 months? & $300(75 \%)$ & $66(16.5 \%)$ & $34(8.5 \%)$ \\
\hline Have you ever shared antibiotics with your entourage? & $67(16.8 \%)$ & $329(82.3 \%)$ & $4(1 \%)$ \\
\hline Have you ever stopped antibiotic treatment earlier than expected? & $263(65.8 \%)$ & $125(31.3 \%)$ & $12(3 \%)$ \\
\hline Have you ever decreased the frequency of antibiotic administration without health professional advice? & $117(29.3 \%)$ & $278(69.5 \%)$ & $5(1.3 \%)$ \\
\hline Do you ever demand antibiotics during consultations? & $29(7.3 \%)$ & $369(92.3 \%)$ & $2(0.5 \%)$ \\
\hline Are you returning unused or expired medicines to pharmacies or health facilities? & $395(98.8 \%)$ & $4(1 \%)$ & $1(0.3 \%)$ \\
\hline Do you check the expiry dates of medicines? & $151(37.8 \%)$ & $104(26 \%)$ & $145(36.3 \%)$ \\
\hline
\end{tabular}

\subsection{Sources of Supply}

The sources of supply identified were community pharmacy (81\%), entourage (12\%), leftover antibiotics from previous prescriptions (5\%) and illicit drugs market (2\%) (Figure 1).

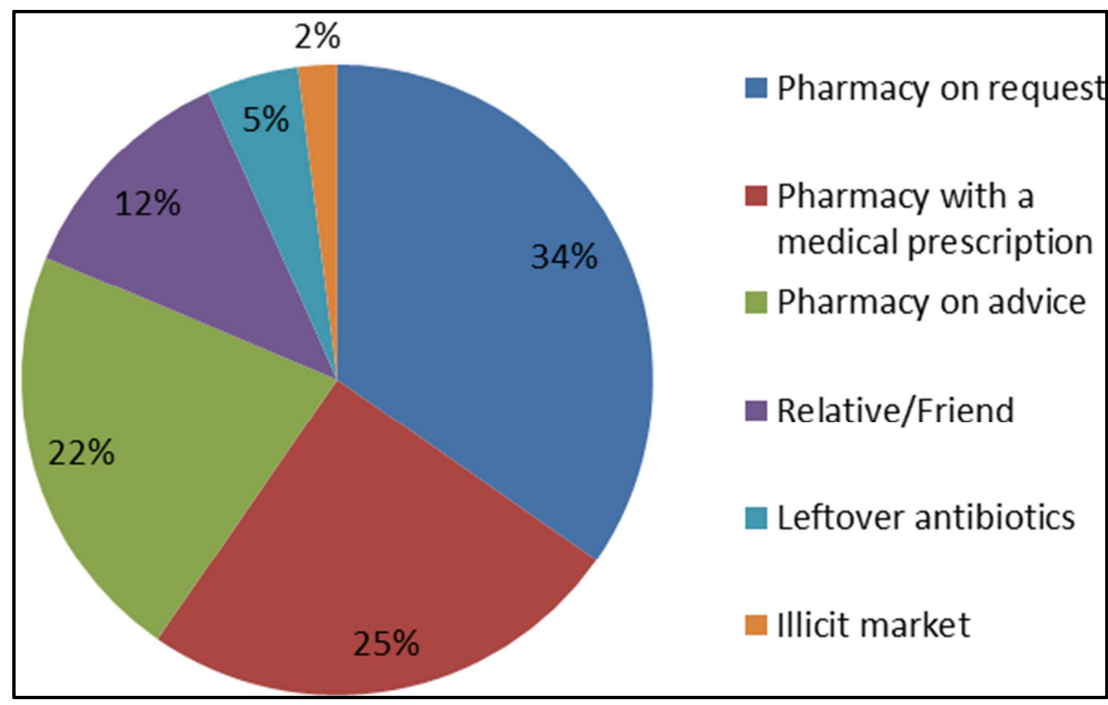

Figure 1. Sources of antibiotics supply, Rufisque, Senegal, November-December 2017, (N=300).

\subsection{Reasons for Practices Towards Antibiotics Use}

\subsubsection{Antibiotic Consumption}

The top three reasons cited by individuals were cough (14\%), sore throat (13.7\%) and fatigue (13.3\%) (Figure 2).

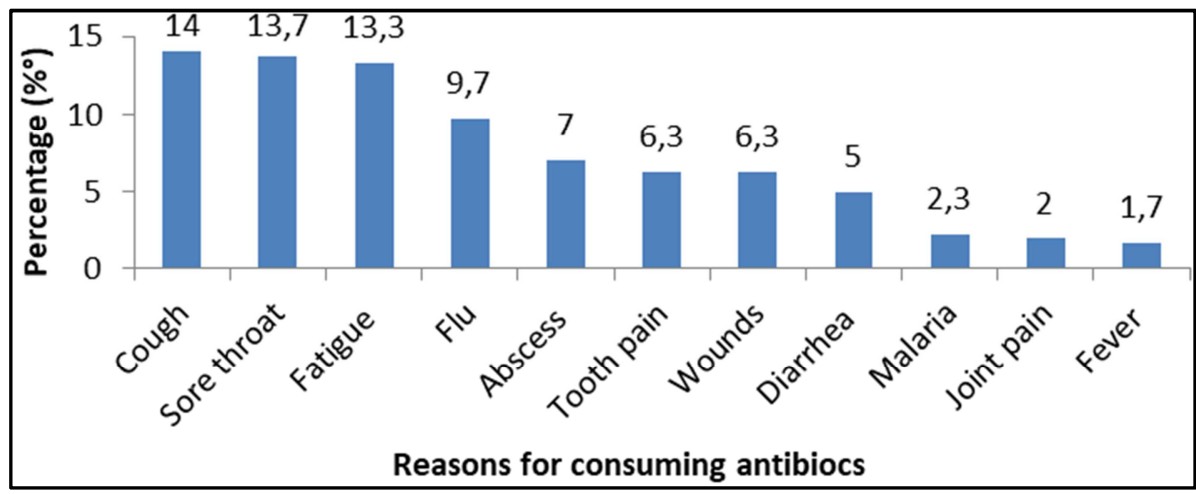

Figure 2. Participants' reasons for consuming antibiotics, Rufisque, Senegal, November-December 2017, (N=400). 


\subsubsection{Antibiotics'Sharing}

The main reasons were lack of money to consult a health professional (52\%), lack of interest in the hospital (21\%) and remoteness to health facility (10\%) (Figure 3).

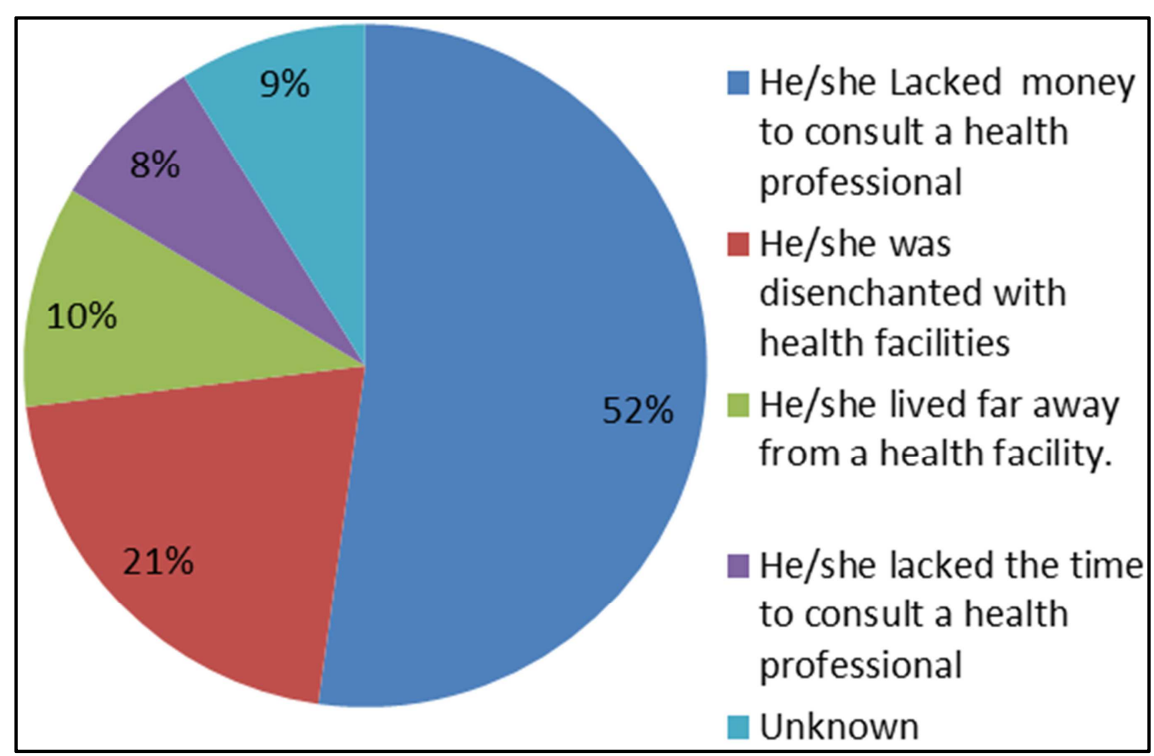

Figure 3. Reasons for sharing antibiotics, Rufisque, Senegal, November-December 2017 (N=67).

\subsubsection{Treatment Noncompliance}

The circumstances of antibiotic treatment interruption included, among others, disappearance of symptoms (63\%) and occurrence of side effects (3\%) (Figure 4$)$.

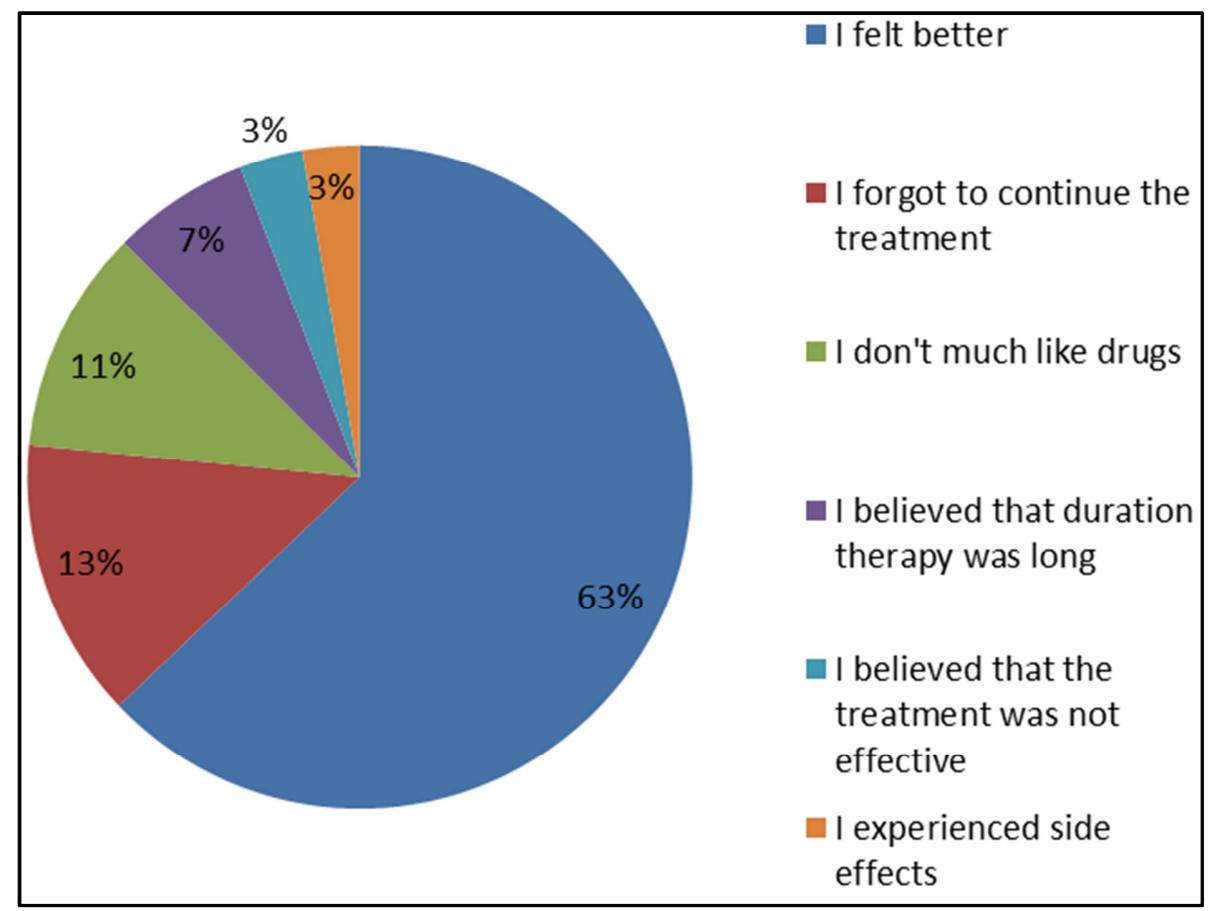

Figure 4. Reasons for interrupting antibiotic therapy, Rufisque, Senegal, November-December 2017 (N=263).

As for the reduction of the frequency of antibiotics administration, the main reasons were disappearance of symptoms $(29 \%)$, lack of time (25\%) and disgust for drugs (21\%) (Figure 5). 


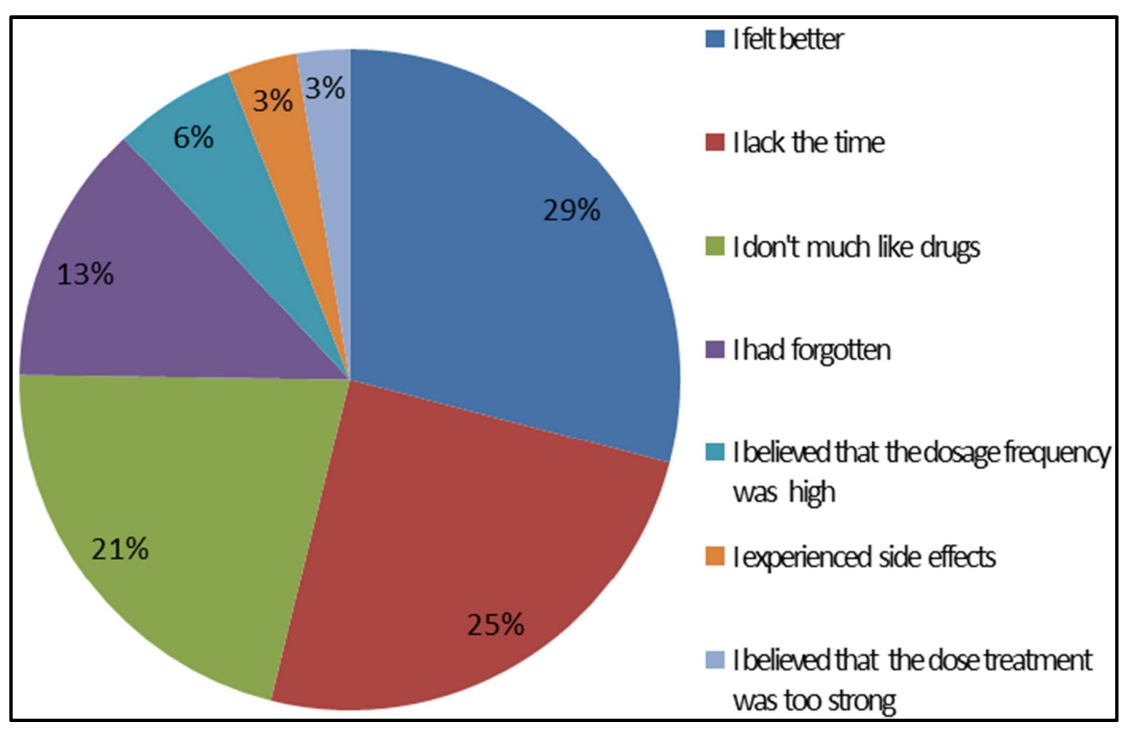

Figure 5. Reasons for diminishing frequency taken, Rufisque, Senegal, November-December 2017, (N=117).

\subsection{Determinants of UAWP}

In bivariate analysis, gender, professional status and education were associated with UAWP. In contrast, multivariate analysis identified only education as a determinant of UAWP. Uneducated people were 2.7 times more exposed to the UAWP than those who were educated $(\mathrm{OR}=2.7$ and $\mathrm{p}$-value $=0.002)($ Table 3$)$.

Table 3. Bivariate and multivariate analysis for relationship between participants'socio-demographic characteristics (SDC) and UAWP, Rufisque, Senegal, November-December 2017, (N=300).

\begin{tabular}{|c|c|c|c|c|c|c|c|c|}
\hline \multirow{2}{*}{ SDC } & \multicolumn{2}{|c|}{ UAWP } & \multicolumn{3}{|c|}{ Bivariate analysis } & \multicolumn{3}{|c|}{ Logistic regression } \\
\hline & Yes & No & OR & IC95\% & p-value & $\mathrm{OR}_{\mathrm{a}}$ & IC95\% & p-value \\
\hline \multicolumn{9}{|l|}{ Age (years) } \\
\hline$\leq 40$ & 132 & 47 & 0.85 & $0.5-1.46$ & 0.54 & & & \\
\hline$>40$ & 93 & 28 & 1 & & & & & \\
\hline \multicolumn{9}{|l|}{ Gender } \\
\hline Male & 130 & 31 & 1.9 & $1.1-3.3$ & $0.013^{*}$ & 1.5 & $0.8-2.7$ & 0.203 \\
\hline Female & 95 & 44 & 1 & & & & & \\
\hline \multicolumn{9}{|l|}{ Marital status } \\
\hline Married & 127 & 41 & 1.07 & $0.6-1.8$ & 0.788 & & & \\
\hline Unmarried & 98 & 34 & 1 & & & & & \\
\hline \multicolumn{9}{|l|}{ Education } \\
\hline Yes & 96 & 52 & 1 & & & 1 & & \\
\hline No & 129 & 23 & 3.04 & $1.7-5.3$ & $<10^{-3 *}$ & 2.7 & $1.5-4.8$ & $0.002 * *$ \\
\hline \multicolumn{9}{|c|}{ Professional statut } \\
\hline Employed & 147 & 39 & 1.7 & $1.02-2.9$ & $0.039 *$ & 1.3 & $0.7-2.3$ & 0.438 \\
\hline Unemployed & 78 & 36 & 1 & & & & & \\
\hline \multicolumn{9}{|c|}{ Proximity to a community pharmacy } \\
\hline Yes & 105 & 36 & 0.95 & $0.56-1.6$ & 0.84 & & & \\
\hline No & 120 & 39 & 1 & & & & & \\
\hline \multicolumn{9}{|c|}{ Proximity to a health facility } \\
\hline Yes & 146 & 48 & 1.04 & $0.6-1.79$ & 0.889 & & & \\
\hline No & 79 & 27 & 1 & & & & & \\
\hline
\end{tabular}

$*=$ significative in bivariate analysis, ${ }^{* *}=$ significative in multivariate analysis

\section{Discussion}

Antibiotic resistance represents a threat to public health, global security and sustainable development [23]. It is serious as it concerns today antibiotics of last resort like colistin and carbapenems. This situation raises fears of reaching the tipping point, that is, a return to the preantibiotic era $[11,12]$. Senegal is not immune to this scourge in view of the results of the WHO JEE [18]. This situation is mainly due to the excessive consumption of antibiotics, of which one of the main actors is the general public [8]. Therefore, global public awareness campaign is one of the most recommended solutions [8]. Understanding the population's practices regarding antibiotics is a prerequisite for any awareness-raising activity. This study, conducted in an urban setting, is part of this framework. It has resulted in poor results. They will undoubtedly guide decision-making 
and set up community awareness campaigns.

\subsection{Antibiotic Consumption}

\subsubsection{Prevalence of Antibiotic Therapy}

In this study, $75 \%$ of people had taken an antibiotic treatment in the last 12 months preceding the survey. This prevalence was comparable to that found in Kuwait (72.8\%) [24], while it was higher than those found in Ethiopia (46.7\%) [25] and Kosovo (58.7\%) [26].

These results suggest that antibiotics are overused. A recent study showed that global antibiotic consumption increased by $65 \%$ between 2000 and 2015 [27]. The main concern is that this overconsumption concerns, among others, antibiotics of last resort. If no action is taken now, antibiotic overuse is projected to increase by $15 \%$ between 2015 and 2030 [27]. It may reflect over-prescription, over-the-counter access to antibiotics and, more recently, online shopping, which is widespread in many countries [7]. This situation is worrying given the close relationship between antibiotic overuse and resistance [8].

\subsubsection{The Reasons}

In this study, respiratory infections were the main reason for antibiotic exposure (41\%) while diarrhea accounted for $5 \%$. The use of antibiotics to treat these infections would be debatable because they are of viral origin in most cases. Yet according to Jim O'Neill's report [8], antibiotics are being misused against these diseases. On the one hand, in the United States, every year 40 million people suffering from respiratory infections receive antibiotics. Among them, 27 million $(67.5 \%)$ are treated unnecessarily. On the other hand, in middle-income countries, 500 million courses of antibiotic are used during episodes of diarrheal illness [8]. Further studies would be needed to identify the most consumed classes of antibiotics.

\subsubsection{Sources of Supply}

A large amount of antibiotic prescriptions is used in the community at heath professional advice or through selfmedication [8]. Sometimes, doctors prescribe antibiotics without using a diagnostic tool [8]. In this study, only $25 \%$ of respondents consumed antibiotics following a medical prescription which was dispensed in a community pharmacy.

On the other hand, the UAWP was found in $75 \%$ of participants who had taken antibiotic treatment in the last twelve months preceding the survey. This result reflects a high self-medication practice. The community pharmacy represents the source of supply for $56 \%$ of people. Financial interest could be the cause of this malpractice. It is established that some pharmacists think to retain their customers through this form of dispensing. According to them, patients always have the opportunity to obtain antibiotics without a medical prescription in another pharmacy in case of refusal [28]. On the other hand, in Africa, community pharmacy is sometimes the first level of outpatient care. This phenomenon is favored by the short waiting time, the absence of consultation fees and the possibility of adapting the treatment options according to the patient's financial capacity [5]

Other sources of supply were also identified in our study. First, $12 \%$ of people reported getting their antibiotic treatment from a parent or friend. Then $5 \%$ reused antibiotics leftover from their previous prescription. This proportion was $70.4 \%$ in Kosovo [26]. Lastly, 2\% sourced antibiotics from the illicit market. These practices may reflect inaccessibility to healthcare and weak regulation of the pharmaceutical sector in developing countries [8]. In West Africa, many antibiotics are available in popular markets [29]. A systematic review has shown that self-medication is a common practice that varies from region to region. In Africa, the prevalence is $40.6 \%$ while in Asia, the Middle East and South America, it is estimated at $38 \%, 34.1 \%$ and $44.1 \%$, respectively [30]. This irrational practice shows that a significant amount of antibiotics is used unnecessarily while at the same time patients who are in need do not have access to them. As a result, it contributes to the waste of resources and the emergence of resistance.

The study is carried out in an urban setting. Thus, it can be assumed that the magnitude of these malpractices towards antibiotics use could be higher in rural areas given the low educational level of its inhabitants and the low presence of qualified health professionals.

The results of this study showed that antibiotic consumption is high. In addition, the reasons were sometimes unfounded and the sources of supply were inadequate. Strategies exist to reduce the overuse of antibiotics. These include the implementation of rapid diagnostic tests in both health facilities and community pharmacies, access to drinking water and sanitation, vaccination, hand washing and regulation of the pharmaceutical sector [8]. However, it has been shown that child mortality in low and middle resource countries is more attributed to inaccessibility to antibiotics than to bacterial resistance [31]. So these countries are divided between improving access to antibiotics and reducing their consumption [31]. Therefore, special attention should be paid to these countries. It is imperative to initiate strategies for moving towards universal health coverage that will be complemented by rational use of antibiotics [32].

\subsection{Antibiotics'Sharing}

In this study, $16.8 \%$ of the participants said that they shared their antibiotic treatment with their relative or friend. Antibiotics' sharing is associated with inappropriate use and, consequently, with resistance [24]. The main reasons given were lack of money to consult a health professional (52.2\%) and lack of interest of patients for health facilities (20.9\%). Beyond inaccessibility to heath care services, this result eventually raises the issue of dissatisfaction and deterioration of people's trust in the health system. This situation could lead to delayed diagnosis and management of diseases. In the event that these are due to resistant bacteria, their dissemination within the community could happen quickly. Populations should be made aware of the risks associated with antibiotics' sharing. At the same time, reception in health facilities should be improved. 


\subsection{Treatment Noncompliance}

Poor patient compliance with antibiotic treatment is recognized as a risk factor for resistance [3]. In this study, it manifested in two ways. First, $65.8 \%$ participants said they experienced stopping their antibiotic treatment earlier than expected. Second, 29.3\% reported having reduced the frequency of medication. The disappearance of symptoms and the occurrence of side effects were, among others, the reasons given by respondents. These results revealed that people don't respect the schedule of antibiotic administration and the consequences to which they expose themselves. This can be explained by poor health professional-patient communication. In developing countries, the patient / doctor ratio is high. This increases the workload of health providers. It results in a lack of time preventing patient awareness about treatment compliance and its importance [5]. In Senegal, most of the prescribers are nurses with a low level of training. Pharmacists could play an important role given their accessibility and status as drug expert. They can provide counselling to patient about dosage intervals, side effects and interactions with other medications or food [3].

\subsection{Demand for Antibiotics}

Patients often require antibiotics from their doctors [8]. In this study, this practice was found in $7.3 \%$ of those surveyed. It could lead to antibiotic resistance. It could be explained by insufficient health literacy in individuals [34]. This proportion, although low, showed that it is necessary to convince people not to demand antibiotics in order to limit unnecessary and excessive use of antibiotics [8]. To this end, the skills of health professionals on communication techniques need to be strengthened to promote behavioral change in populations [33].

\subsection{Home Storage of Medicines}

The results showed that $98.8 \%$ of participants said they had never returned expired or unused medicines to pharmacies or hospitals. In Angola, a study showed that $35.1 \%$ of households stockpiled medicines. About $40 \%$ were antibiotics [34]. These results would shed light on two situations. First, they assume that the treatments are not prescribed and / or dispensed according to the required duration [35]. Secondly, they could reflect poor medication compliance [36]. In both cases, these practices expose patients to future self-medication and consequently to bacterial resistance [34]. Thus, it would be essential not only to sensitize patients about the importance of avoiding home storage of unwanted medicines but also to evaluate prescribing and dispensing practices.

\subsection{Checking Drugs Expiration Dates}

In this survey, $37.8 \%$ of respondents said they had never checked the expiry dates of medicines. This result is in contradiction with the one highlighted in Lebanon where $83.2 \%$ of people surveyed reported checking the expiry dates
[37]. Populations should be made aware of the importance of checking the expiry date of medicines. Indeed, a study conducted in Nigeria showed that expired antibiotics may have clinical consequences such as resistance, side effects and treatment failure [38].

\subsection{Determinants of $U A W P$}

The study showed that only education was significantly associated with the UAWP. In fact, uneducated people have recourse to this practice 2.7 times more than those who are educated. Yet a systematic review of 34 studies and that of Ayalew MB conducted in Ethiopia revealed that age, gender, marital status, occupational status are determinants of selfmedication [30, 39]. In the present study, the absence of a significant relationship between distance from participants' home to a health facility or a community pharmacy and UAWP assumes that populations practice self-medication using leftover antibiotics or those received from their entourage. These results show that sensitization campaigns on the rational use of antibiotics should particularly target the uneducated people or those with a low level of education. The areas of awareness will focus on antibiotics' sharing and in-home antibiotic storage.

Additional studies are needed to identify other determinants of non-prescription antibiotic use in Senegal, particularly in rural areas.

\subsection{Study Limitations}

In this study, the prevalence of antibiotic consumption was estimated based on the respondents' statement. Thus, it could be underestimated. We recommend conducting surveys in hospitals and outpatient departments to determine the level of antibiotic consumption using an internationally approved indicator such as the defined daily dose [9].

The study was cross-sectional and appealed to respondents' memory. So, it could have a memory bias.

Finally, the generalizability of the results would be questionable since the research was conducted in the suburbs of Dakar. In rural areas, the practices could be different.

However, these limitations do not undermine the interest of the study. First, a 12-month setback was used for memories on antibiotic use. This would limit the memory bias. On the other hand, this study is the first in Senegal. Its interest lies in the fact that it has yielded relevant results that health authority could use to prepare and implement interventions such as public awareness and training of health professionals on the rational use of antibiotics.

\section{Conclusion}

This study was conducted in an urban setting. It focused on the assessment of general population's practices regarding antibiotic use. It has shown disheartening results such as excessive consumption of antibiotics, various and inadequate sources of supply, self-medication, antibiotics' sharing and treatment noncompliance. Uneducated people use non- 
prescription antibiotics more than those who are educated. These irrational practices contribute to the selection of antibiotic-resistant bacteria. The results of this study have, undoubtedly, contributed to generating new knowledge about people's use of antibiotics. Therefore, they will enable policy makers to implement relevant interventions to streamline the public's practices towards antibiotics and thus prevent and control antibiotic resistance. These interventions include educating health professionals and the general public, especially the uneducated people, reducing the incidence of infectious diseases through high impact strategies such as vaccination, hand washing, access to drinking water and sanitation and regulating pharmaceutical sector. However, further studies should be conducted in other parts of Senegal, including rural areas. These studies would strive to identify the most commonly used antibiotics and the extent of inappropriate practices and their determinants among both health professionals and patients.

\section{Acknowledgements}

We sincerely thank the residents of Rufisque who accepted to participate in this study.

\section{Competing Interests}

The authors declare no conflict of interest. This research received no external funding.

\section{References}

[1] Mohr KI. History of Antibiotics Research. Curr Top Microbiol Immunol. 2016; 398: 237-272. doi: 10.1007/82_2016_499. Review. PubMed PMID: 27738915.

[2] Ventola CL. The antibiotic resistance crisis: part 1: causes and threats. P T. 2015 Apr; 40 (4): 277-83. PubMed PMID: 25859123; PubMed Central PMCID: PMC4378521.

[3] Mason T, Trochez C, Thomas R, Babar M, Hesso I, Kayyali R. Knowledge and awareness of the general public and perception of pharmacists about antibiotic resistance. BMC Public Health. 2018 Jun 8; 18 (1): 711. doi: 10.1186/s12889018-5614-3. PubMed PMID: 29884154; PubMed Central PMCID: PMC5994078.

[4] Knufmann-Happe K. Réponses politiques à la résistance aux antimicrobiens - la stratégie allemande. In AMR Control. Surmonter La Résistance Aux Antimicrobiens, 3rd ed.; WAAAR; Global Health Dynamics: Suffolk, UK, 2017; Volume 1, pp. 16-20. ISBN 978-0-9576072-7-9. Available online: http://resistancecontrol.info/wpcontent/uploads/2018/05/16-20.pdf (accessed on 16 October 2018).

[5] Ayukekbong JA, Ntemgwa M, Atabe AN. The threat of antimicrobial resistance in developing countries: causes and control strategies. Antimicrob Resist Infect Control. 2017 May 15; 6: 47. doi: 10.1186/s13756-017-0208-x. eCollection 2017. Review. PubMed PMID: 28515903; PubMed Central PMCID: PMC5433038.
[6] The World Alliance Against Antibiotic Resistance (WAAAR). AMR Control in discussion with Dr Marc Sprenger. In AMR Control 2018. Overcoming Global Antimicrobial Resistance; WAAAR; Global Health Dynamics: Suffolk, UK, 2018; pp. 10-12. ISBN 978-0-9576072-7-9. Available online: http://resistancecontrol.info/wp-content/uploads/2018/08/1012.pdf (accessed on 1 November 2018).

[7] Organisation Mondiale de la Santé. Plan D'action Mondial Pour Combattre la Résistance Aux Antimicrobiens; OMS: Généve, Suisse, 2016. Available online: http://apps.who.int/iris/bitstream/handle/10665/249548/978 9242509762 fre.pdf; jsessionid=6BA7B094CA69BC758FC5 2F00A7E179E0? sequence $=1$ (accessed on 10 October 2018).

[8] O’Neill, J. Tackling Drug-Resistant Infections Globally: Final Report and Recommendations. Review on Antimicrobial Resistance. Wellcome Trust and HM Government 2016. Available online: https://amrreview.org/sites/default/files/160525_Final\%20paper_with\%2 0cover.pdf (accessed on 16 October 2018).

[9] World Health Organization. Global Antimicrobial Resistance Surveillance System (GLASS) Report: Early implementation 2016-2017. WHO: Geneva, Switzerland, 2017. Licence: CC BY-NC-SA 3.0 IGO; 2017. ISBN 978-92-4-151344-9. Available online: http://apps.who.int/iris/bitstream/handle/10665/259744/97892 41513449-eng.pdf? sequence $=1$ (accessed on 16 October 2018).

[10] World Health Organization. Antimicrobial Resistance: Global Report on Surveillance. WHO: Geneva, Switzerland, 2014. ISBN $\quad \begin{array}{llllll}978 & 92 & 4 & 156474 & 8\end{array}$ http://apps.who.int/iris/bitstream/handle/10665/112642/97892 41564748 eng.pdf? sequence $=1$ \&isAllowed $=y$ (accessed on 18 October 2018).

[11] Richter SE, Miller L, Uslan DZ, Bell D, Watson K, Humphries R, McKinnell JA. Risk Factors for Colistin Resistance among Gram-Negative Rods and Klebsiella pneumoniae Isolates. J Clin Microbiol. 2018 Aug 27; 56 (9). pii: e00149-18. doi: 10.1128/JCM.00149-18. Print 2018 Sep. PubMed PMID: 29976595; PubMed Central PMCID: PMC6113453.

[12] Liu YY, Wang Y, Walsh TR, Yi LX, Zhang R, Spencer J, et al. Emergence of plasmid-mediated colistin resistance mechanism MCR-1 in animals and human beings in China: a microbiological and molecular biological study. Lancet Infect Dis. 2016 Feb; 16 (2): 161-8. doi: 10.1016/S14733099(15)00424-7. Epub 2015 Nov 19. PubMed PMID: 26603172.

[13] Camara M, Mane MT, Ba-Diallo A., Dieng A, Diop-Ndiaye H, Karam F, et al. Extended-spectrum beta-lactamase- and carbapenemase-producing Enterobacteriaceae clinical isolates in a Senegalese teaching hospital: A cross sectional study. Afr J Microbiol Res. 2017 Nov 28; 11 (44): 1600-1605. DOI: 10.5897/AJMR2017.8716.

[14] World Bank Group. Drug-Resistant Infections: A Threat to Our Economic Future; Final Report; WBG: Washington, DC, USA, 2017. Available online: http://documents.worldbank.org/curated/en/\%20323311493 396993758/pdf/114679-REVISED-v2-Drug-ResistantInfections-Final-Report.pdf (accessed on 16 October 2018). 
[15] Carlet J; members of the WAAAR. World Alliance Against Antibiotic Resistance: The WAAAR declaration against antibiotic resistance. Med Intensiva. 2015 Jan-Feb; 39 (1): 349. doi: 10.1016/j.medin.2014.10.004. Epub 2014 Dec 17. PubMed PMID: 25534919.

[16] World Alliance Against Anrtibiotic Resistance. AMR Control. Available online: http://resistancecontrol.info/ (accessed on 20 October 2018).

[17] Coll-Seck, A. M.; Seck, I.; Sow, A. I.; Ndoye, B.; Ngom, B.; Diack, P. A. La gouvernance contre la résistance aux antimicrobiens en Afrique: Faire face quand les ressources sont limitées-L'exemple du Sénégal. In AMR Control. Surmonter La Résistance Aux Antimicrobiens, 3rd ed.; WAAAR; Global Health Dynamics: Suffolk, UK, 2017; Volume 1, pp. 10-15. ISBN 978-0-9576072-7-9. Available online: http://resistancecontrol.info/wpcontent/uploads/2018/05/10-15.pdf (accessed on 20 September 2018).

[18] Organisation Mondiale de la santé. Évaluation Externe Conjointe des Principales Capacités RSI de la République du Sénégal; Rapport de Mission: 28 Novembre-2 Décembre 2016; OMS: Généve, Suisse, 2017. Available online: http://apps.who.int/iris/bitstream/handle/10665/255765/WHOWHE-CPI-2017.31-fre.pdf? sequence $=1$ (accessed on 19 September 2018).

[19] Agence Nationale de la Statistique et de la Démographie. Projection de la Population de la Région de Dakar, 2013-2025; ANSD: Dakar, Sénégal, 2013. Available online: $\mathrm{http} / / /$ www.ansd.sn/ressources/publications/indicateurs/Projection s-demographiques-2013-2025+.htm (accessed on 16 May 2018).

[20] Agence Nationale de la Statistique et de la Démographie et Fonds des Nations Unies pour l'enfance. MICS V Dakar Enquête par Grappes à Indicateurs Multiples 2015-2016; Rapport Final; ANSD: Dakar, Sénégal, 2016. Available online:

http://www.ansd.sn/ressources/publications/RAPPORT\%20MI CS\%20Urbaine\%20Dakar\%202015-

2016_FINAL\%20novembre_version\%20finale \%20.pdf (accessed on 17 May 2018).

[21] Raosoft, Inc. Raosoft Sample Size Calculator. 2004. Available online: http://www.raosoft.com/samplesize.html (accessed on 30 October 2017).

[22] Hosmer DWJ, Lemeshow S. Applied Logistic Regression, 2nd ed.; Wiley-Interscience Publication: New York, NY, USA, 2000; p. 392.

[23] A Global Declaration on Appropriate Use of Antimicrobial Agents across the Surgical Pathway. Surg Infect (Larchmt). 2017 Nov/Dec; 18 (8): 846-853. doi: 10.1089/sur.2017.219. PubMed PMID: 29173054.

[24] Awad AI, Aboud EA. Knowledge, attitude and practice towards antibiotic use among the public in Kuwait. PLoS One. $2015 \quad$ Feb 12; $10 \quad$ (2): e0117910. doi: 10.1371/journal.pone.0117910. eCollection 2015. PubMed PMID: 25675405; PubMed Central PMCID: PMC4326422.

[25] Gebeyehu E, Bantie L, Azage M. Inappropriate Use of Antibiotics and Its Associated Factors among Urban and Rural Communities of Bahir Dar City Administration, Northwest Ethiopia. PLoS One. 2015 Sep 17; 10 (9): e0138179. doi: 10.1371/journal.pone.0138179. eCollection 2015. PubMed PMID: 26379031; PubMed Central PMCID: PMC4574735.
[26] Zajmi D, Berisha M, Begolli I, Hoxha R, Mehmeti R, MulliqiOsmani $\mathrm{G}$, et al. Public knowledge, attitudes and practices regarding antibiotic use in Kosovo. Pharm Pract (Granada). 2017 Jan-Mar; $15 \quad$ (1): $827 . \quad$ doi: 10.18549/PharmPract.2017.01.827. Epub 2017 Mar 15. PubMed PMID: 28503216; PubMed Central PMCID: PMC5386617.

[27] Klein EY, Van Boeckel TP, Martinez EM, Pant S, Gandra S, Levin SA, et al. Global increase and geographic convergence in antibiotic consumption between 2000 and 2015. Proc Natl Acad Sci U S A. 2018 Apr 10; 115 (15): E3463-E3470. doi: 10.1073/pnas.1717295115. Epub 2018 Mar 26. PubMed PMID: 29581252; PubMed Central PMCID: PMC5899442.

[28] Hadi MA, Karami NA, Al-Muwalid AS, Al-Otabi A, AlSubahi E, Bamomen A, et al. Community pharmacists' knowledge, attitude, and practices towards dispensing antibiotics without prescription (DAwP): a cross-sectional survey in Makkah Province, Saudi Arabia. Int J Infect Dis. 2016 Jun; 47: 95-100. doi: 10.1016/j.ijid.2016.06.003. Epub 2016 Jun 22. PubMed PMID: 27343987.

[29] Ouedraogo AS, Jean Pierre H, Bañuls AL, Ouédraogo R, Godreuil, S. Émergence et diffusion de la résistance aux antibiotiques en Afrique de l'Ouest: Facteurs favorisants et évaluation de la menace. Med. Sante Trop. 2017, 27, 147-154.

[30] Ocan M, Obuku EA, Bwanga F, Akena D, Richard S, OgwalOkeng J, Obua C. Household antimicrobial self-medication: a systematic review and meta-analysis of the burden, risk factors and outcomes in developing countries. BMC Public Health. 2015 Aug 1; 15: 742. doi: 10.1186/s12889-015-21093. Review. PubMed PMID: 26231758; PubMed Central PMCID: PMC4522083.

[31] Nadimpalli M, Delarocque-Astagneau E, Love DC, Price LB, Huynh BT, Collard JM, et al.; Bacterial Infections and antibiotic-Resistant Diseases among Young children in lowincome countries (BIRDY) Study Group. Combating Global Antibiotic Resistance: Emerging One Health Concerns in Lower- and Middle-Income Countries. Clin Infect Dis. 2018 Mar 5; 66 (6): 963-969. doi: 10.1093/cid/cix879. PubMed PMID: 29346620.

[32] Bloom G, Merrett GB, Wilkinson A, Lin V, Paulin S. Antimicrobial resistance and universal health coverage. BMJ Glob Health. 2017 Oct 31; 2 (4): e000518. doi: 10.1136/bmjgh-2017-000518. eCollection 2017. Review. PubMed PMID: 29225955; PubMed Central PMCID: PMC5717966.

[33] Salm F, Ernsting C, Kuhlmey A, Kanzler M, Gastmeier P, Gellert P. Antibiotic use, knowledge and health literacy among the general population in Berlin, Germany and its surrounding rural areas. PLoS One. 2018 Feb 23; 13 (2): e0193336. doi: 10.1371/journal.pone.0193336. eCollection 2018. PubMed PMID: 29474470; PubMed Central PMCID: PMC5825110.

[34] Ocan M, Bbosa GS, Waako P, Ogwal-Okeng J, Obua C. Factors predicting home storage of medicines in Northern Uganda. BMC Public Health. 2014 Jun 26; 14: 650. doi: 10.1186/1471-2458-14-650. PubMed PMID: 24964746; PubMed Central PMCID: PMC4229978.

[35] Wang X, Lin L, Xuan Z, Li L, Zhou X. Keeping Antibiotics at Home Promotes Self-Medication with Antibiotics among Chinese University Students. Int J Environ Res Public Health. 2018 Apr 5; 15 (4). pii: E687. doi: 10.3390/ijerph15040687. PubMed PMID: 29621165; PubMed Central PMCID: PMC5923729. 
[36] Togoobaatar G, Ikeda N, Ali M, Sonomjamts M, Dashdemberel S, Mori R, et al. Survey of non-prescribed use of antibiotics for children in an urban community in Mongolia. Bull World Health Organ. 2010 Dec 1; 88 (12): 930-936. doi: 10.2471/BLT.10.079004.

[37] Mouhieddine TH, Olleik Z, Itani MM, Kawtharani S, Nassar $\mathrm{H}$, Hassoun R, et al. Assessing the Lebanese population for their knowledge, attitudes and practices of antibiotic usage. J Infect Public Health. 2015 Jan-Feb; 8 (1): 20-31. doi: 10.1016/j.jiph.2014.07.010. Epub 2014 Aug 22. PubMed PMID: 25154919.
[38] Ogunshe A, Adinmonyema P. Evaluation of bacteriostatic potency of expired oral paediatric antibiotics and implications on infant health. Pan Afr Med J. 2014 Dec 15; 19: 378. doi: 10.11604/pamj.2014.19.378.2156.

[39] Ayalew MB. Self-medication practice in Ethiopia: a systematic review. Patient Prefer Adherence. 2017 Mar 1; 11: 401-413. doi: 10.2147/PPA.S131496. eCollection 2017. Review. PubMed PMID: 28280312; PubMed Central PMCID: PMC5338978. 